\title{
Reasons for not seeking early dental care in patients presenting in the exodontia department at a Tertiary Care Hospital in Lahore, Pakistan.
}

\footnotetext{
1. BDS

House Officer

De'Montmorency College of Dentistry Fort Road, Lahore.

2. BDS

House Officer

De'Montmorency College of

Dentistry Fort Road, Lahore.

3. BDS

House Officer

De'Montmorency College of Dentistry Fort Road, Lahore.

4. BDS, M.Phil

Assistant Professor/HOD Oral

Biology

Rashid Latif Dental College, $35 \mathrm{Km}$

Ferozpur Road, Lahore.
}

Correspondence Address:

Dr. Varda Hussain

63 K1 Wapda Town Lahore, Pakistan.

vardahussain@gmail.com

Article received on:

30/05/2020

Accepted for publication:

$21 / 12 / 2020$

\begin{abstract}
Anoosha Waseem ${ }^{1}$, Varda Hussain², Rida Binte Zahid ${ }^{3}$, Maliha Shahbaz ${ }^{4}$
\end{abstract}
ABSTRACT... Objective: The aim was to gain insight on patient factors and administrative shortcomings in the dental health department that prevent patients from seeking timely dental care. Study Design: Cross Sectional Survey. Setting: Punjab Dental Hospital, Lahore, Pakistan. Period: 7 January 2020 to 28 February 2020. Material \& Methods: A structured close ended questionnaire was filled by information obtained from 400 patients that presented in the Exodontia OPD requiring extractions due to irreversible tooth damage. The data was collected from 244 (61\%) females and 156 (39\%) males. It was analyzed using SPSS version 20.0 and post stratification chi-square test was applied to see the significance of all comparative statistics. $P$ value of $<0.05$ was taken as significant. Results: Out of 400 patients, 350 had not visited a dentist when the symptoms first appeared. Of these $n=213(60.86 \%)$ were females and $n=137$ $(39.14 \%)$ were males. Majority of the patients were in the age range of 40-65 years and belonged to the low socioeconomic class $n=213(60.9 \%)$. The main causes of patients presenting now were pain and swelling. The major reasons reported for delayed visit were: "Self-medication" $n=113(24.57 \%)$," Symptoms will resolve on their own" $n=79(17.17 \%)$," No awareness" $n=64$ (13.91\%)," Non serious and lazy attitude" $n=39$ (8.48\%) and "Busy schedule" $n=36$ (7.83\%). Conclusion: Our findings suggested that only a small proportion of people visited the dentist when the symptoms first appeared. Most of the patients ignored their symptoms to such an extent that the only possible treatment that could be offered was extraction of the concerned tooth. There was a general misconception that dental diseases are not very serious and can be resolved by over the counter medications. Thus, more dental awareness programs should be incorporated in the government health policy to increase focus on oral health.

Key words: $\quad$ Delayed Dental Care, Dental Awareness, Factors, Government Hospitals, Low Socioeconomic Status.

Article Citation: Waseem A, Hussain V, Zahid RB, Shahbaz M. Reasons for Not Seeking Early Dental Care in Patients Presenting in the Exodontia Department at a Tertiary Care Hospital in Lahore, Pakistan. Professional Med J 2021; 28(8):1107-1113. https://doi.org/10.29309/TPMJ/2021.28.08.5044

\section{INTRODUCTION}

Dental and oral health is an essential part of one's overall health and wellbeing. ${ }^{1}$ Multiple studies have shown that systemic health is affected by different oral diseases especially periodontal disease. .,3 $^{2,3}$ Hence, maintenance of good oral health is essential, which can be achieved by personal oral hygiene practices \& seeking timely professional dental care. ${ }^{4}$ Negligence in doing so leads to several oral diseases such as dental caries and periodontitis which are largely preventable and can be conservatively treated. ${ }^{5}$

The access to dental services depends not only on their provision but also their proper utilization. ${ }^{4}$
Throughout the world, developed countries have made significant improvements in the access by bridging the gap between the aforementioned factors. ${ }^{6}$ Unfortunately in developing countries the gap still remains, and the teeth are often left untreated eventually leading to extractions. ${ }^{7,8}$

Several studies have been carried out to find the reasons for avoiding dental visits. For instance, in a survey conducted in USA, the following reasons were most reported: "Cost" (40.2\%), "No perceived reason to go to the dentist" (32.7\%) and "Lack of time" (14.1\%). ${ }^{9}$ In Australia, the major reasons reported also were cost and lack of time. ${ }^{10}$ On the other hand, in developing countries 
like India the chief factors were: "No need to visit the dentist unless there is pain" (62.5\%), "Dental diseases are not very serious" (51.9\%) and "Lack of time" $(39.3 \%) .{ }^{11}$

A few surveys have been carried out to explore the determinants for delayed treatment in Pakistani population ${ }^{12,13}$ and the most commonly reported findings were financial issues, lack of time, and delayed appointments given by the dentist. ${ }^{13}$ However, not enough studies have been conducted in the government setup where most of the patients belong to the low socioeconomic class.

In Lahore, Pakistan one of the options for dental care service is the tertiary care government hospital where most of the facilities are free of cost or at a very nominal cost. Despite this, there are barriers in seeking regular dental care.

The aim of this study is to gain insight on the patient related factors and administrative shortcomings in the government dental health department that prevent patients from seeking timely dental care. This study targeted patients who presented with dental problems that had exacerbated to such an extent that the only possible solution was non-conservative, aggressive treatment such as dental extraction. The results from this study will facilitate in establishing baseline data that will help us target our efforts in improving patient awareness and dental health services.

\section{MATERIAL \& METHODS}

This cross-sectional survey was conducted after receiving approval from the ethical board of de' Montmorency College of Dentistry/Punjab Dental Hospital (PDH) Lahore (Reference No. 1006/ DCD). The study was conducted from 07-012020 to 28-02-2020 in the Outpatient Department (OPD) of Exodontia in PDH.

A convenient sample of 400 individuals was calculated using the WHO calculator. Questionnaires were given to the doctors to be filled by information obtained from the presenting patients that required extractions due to irreversible tooth damage. Due consent was taken from the patients after explaining the aim and importance of the study. A structured close ended questionnaire was used, addressing the following aspects: age, gender, socioeconomic status, level of education, dental visit history and reasons for not visiting the dentist.

\section{Data Processing and Statistical Analysis}

The data was entered and analyzed using SPSS version 20.0. Descriptive statistics were calculated including mean \pm standard deviation (S.D) of quantitative variables like age. Frequency and percentage were calculated for qualitative variables like gender, socioeconomic status, education level, main cause of visiting now, visit to the dentist after the first symptoms appeared and reasons for delayed visit. Ages of both genders were compared using t-test. The major reasons for delayed visit were stratified for age, gender, education level and socioeconomic status. Post stratification chi-square test was applied to see the significance of all comparative statistics. $P$ value $\leq 0.05$ was taken as significant. The data was also presented in the form of tables and graphs (pie chart and bar graphs).

\section{RESULTS}

The total number of participants was 400 . The age of the patients ranged from 5-76 years with the mean of $36.99 \pm 14.04$. Majority of the patients were in the age range of $40-65$ years. There were 156 males (39\%) and 244 females (61\%), giving a male to female ratio of $1: 1.6$. There was no gender difference with regards to age $(p=0.912)$.

The participants were asked if they had visited the dentist when the symptoms first appeared. Out of the 400 subjects, 50 (12.5\%) responded with "Yes", 19 (38\%) were males and 31 (62\%) were females. Whereas $350(87.5 \%)$ responded with "No", 137 (39.14\%) males and 213 (60.86\%) females. There was no gender difference with regards to the type of response $(p=0.98)$. Figure-1 depicts the distribution of males and females according to their response. 


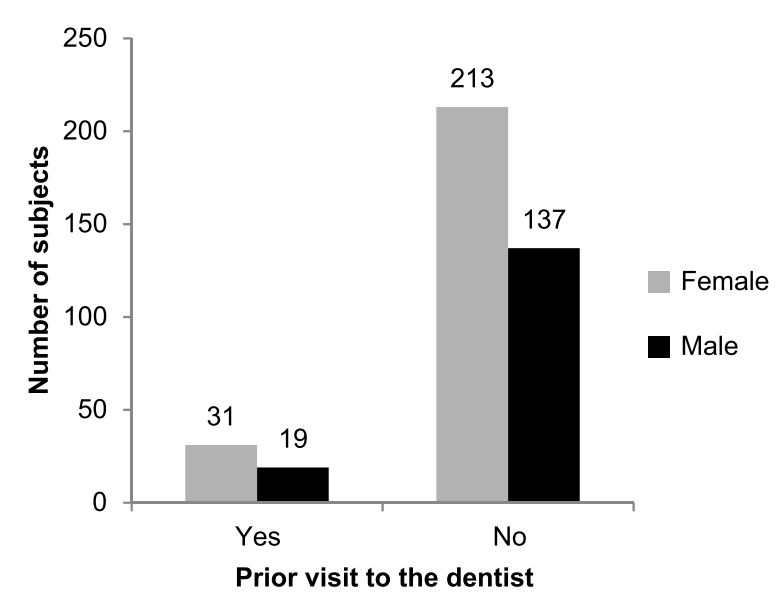

Figure-1. Distribution of males and females according to their response.

The participants who replied with "No" to the previous question were then further interviewed to find out the reasons behind their delayed visit. Out of the 350 patients, the majority 213 (60.9\%) belonged to the lower socioeconomic class, 132 $(37.7 \%)$ from the middle class and $5(1.4 \%)$ were from the upper class.

The educational level of majority of the subjects was below matriculation in 285 (81.4\%) and $65(18.6 \%)$ had received education above matriculation.

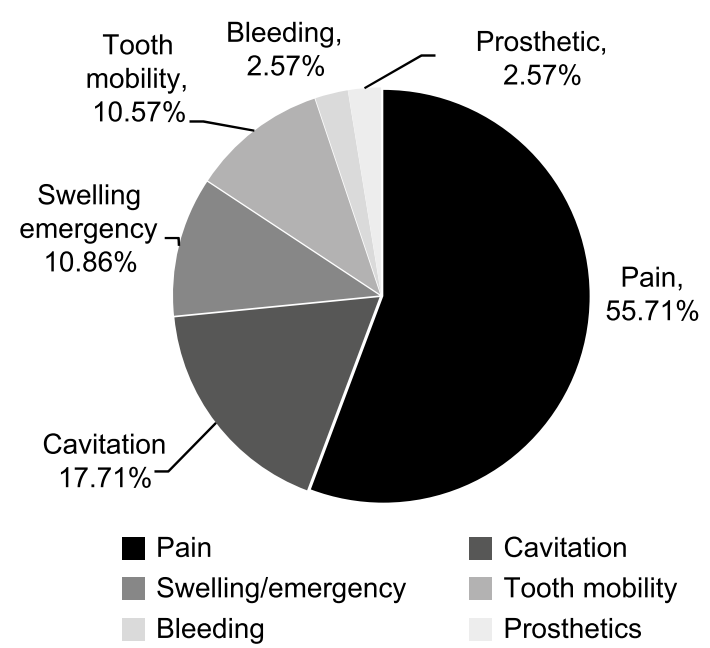

Figure-2. Shows the main causes due to which the patient presented to the exodontia department.

Figure-3 shows the reasons for not seeking dental care along with their frequency and percentage. The main reasons reported were over the counter medications might resolve the symptoms in $113(24.57 \%)$, symptoms will resolve in their own 79 (17.17\%), No awareness about dental treatment 64 (13.91\%), symptoms and dental diseases are not serious 39 (8.48\%), lack of time and busy schedule 36 (7.83\%), the hospital is far and the travel cost is very high 34 (7.39\%), family and domestic issues 28 (6.09\%), systemic health related issues 17 (3.70\%), administrative shortcomings 16 (3.48\%), fear of dental treatment 15 (3.26\%), treatment cost 7 (1.52\%), superstitions $6(1.30 \%)$, dental treatment is harmful during pregnancy $6(1.30 \%)$.

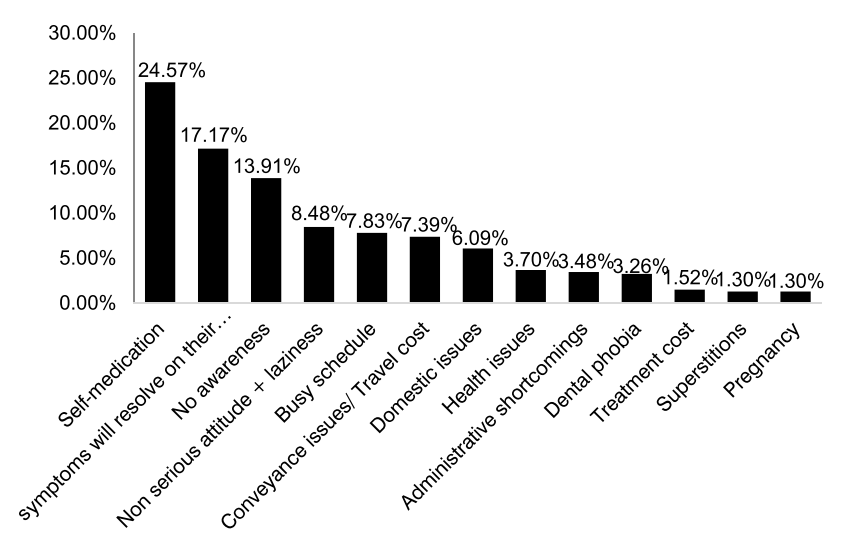

Figure-3. Reasons for not seeking early dental care.

Busy schedule was reported as a reason for delayed visit more in males $27(19.71 \%)$ as compared to females 9 (4.23\%). The same reason was more commonly indicated by people with education above matriculation (15.38\%) as opposed to those below matriculation (9.12\%). Conveyance issues were more prevalent in females $28(13.15 \%)$ than in males 6 (4.38\%). Only $1(0.73 \%)$ males stated domestic issues as a reason contrary to $27(12.68 \%)$ females. More females $n=14(6.57 \%)$ quoted dental phobia in contrast to just $1(0.73 \%)$ males. Health issues were more frequently mentioned as a reason by people of older age i.e. $>50$ years $(6.23 \%)$ than of younger age (2.10\%).

The $p$ values of the first two most common reasons for delayed visit were calculated to find out the significance with respect to age, gender, socioeconomic status and education as shown in Table-l. 


\begin{tabular}{|c|c|c|c|c|}
\hline & $\begin{array}{c}\text { Symptoms will Resolve on } \\
\text { Their Own }\end{array}$ & P-Value & Self-Medication & P-Value \\
\hline $\begin{array}{l}\text { Age } \\
\cdot \quad \leq 30 \text { years } \\
\cdot \quad>30 \text { years }\end{array}$ & $\begin{array}{l}34 \\
45\end{array}$ & 0.235 & $\begin{array}{l}46 \\
67\end{array}$ & 0.353 \\
\hline $\begin{array}{l}\text { Gender } \\
-\quad \text { Male } \\
-\quad \text { Female }\end{array}$ & $\begin{array}{l}35 \\
44\end{array}$ & 0.361 & $\begin{array}{l}48 \\
65\end{array}$ & 0.413 \\
\hline $\begin{array}{l}\text { Socioeconomic Status } \\
\text { - } \quad \text { Low } \\
\text { - } \quad \text { Moderate/High }\end{array}$ & $\begin{array}{l}50 \\
29\end{array}$ & 0.830 & $\begin{array}{l}71 \\
42\end{array}$ & 0.725 \\
\hline $\begin{array}{l}\text { Education } \\
\text { - } \quad \text { Below Matric } \\
\text { - } \quad \text { Above Matric }\end{array}$ & $\begin{array}{l}64 \\
15\end{array}$ & 0.972 & $\begin{array}{l}91 \\
22\end{array}$ & 0.771 \\
\hline
\end{tabular}

Table-I. P-values of major reasons of delayed dental visits with respect to age, gender, socioeconomic status, and education.

P-value of $>0.05$ was considered insignificant.

\section{DISCUSSION}

This study was carried out in order to find out the reasons that prevent the general population from timely utilization of dental care services. The focus of this research was the government sector hospital where despite the nominal cost, early patient presentation was low. Majority of the patients presenting in the main OPD were suffering from irreversible tooth damage and inevitably required extraction of the tooth for which they were referred to the Exodontia department. Hence there was an extreme need to explore the reasons behind such a large proportion of people presenting so late.

The study population consisted mostly of individuals belonging to the low socio-economic class and having limited education similar to the studies conducted in India and Nigeria. ${ }^{14,15}$ These patients had never visited the dentist before and the main reasons for presenting now were extreme pain and swelling.

The most commonly reported reasons in this survey were "self-medication", "symptoms will resolve on their own" and "no awareness" which were consistent with the findings in other studies carried out in Nigeria, India and a research carried out at a private hospital in Pakistan..$^{13,14,15}$ This goes onto show that the problems faced in developing countries are common. This is possibly because people do not usually seek professional dental care even when the symptoms arise but would rather take advice from relatives, nearby pharmacists and quacks. These unprofessional individuals mostly advise over the counter pain killers and antibiotics which do provide temporary symptomatic relief but do not eliminate the cause. The problem stems from the fact that over the counter medications are readily available and are often misused. This unwarranted use leads to abuse and further reduces the possibility of people visiting a dentist for curative treatment.

Lack of awareness shows inability of the population to recognize the need for prophylactic or early dental treatment. This may be ascribed to the abysmal literacy rate and lack of dental education in developing countries like Pakistan. People here fail to understand the seriousness of the dental diseases and hence do not feel that it is important to visit the dentist when a problem initially arises. ${ }^{16}$

However, researches conducted in the developed countries like Australia, Canada and USA were in contrast to our findings. ${ }^{9,10,17}$ This can be accredited to the fact that they have proper systems established to prevent un-prescribed use of the medicines, a high literacy rate and a good understanding of the importance of maintenance of oral health. ${ }^{18}$ The main reasons 
reported in these countries were treatment cost and no dental insurance. Treatment cost has also been reported as one of the major reasons for not seeking timely dental care in other researches such as those conducted in Jordan, Kuwait and India. ${ }^{4,19,20}$ But this is in contrast to our findings as our study was carried out in a government setup where the cost of the dental treatment is very nominal or even free in some cases.

Moreover, in this research, busy schedule being a barrier in utilization of dental services was reported more in males and individuals with education above matriculation. These findings are consistent with the studies done in Jordan. ${ }^{4}$ This is because in the Pakistani society, commonly, men are the bread winners of their family. Hence, they find it difficult to prioritize their oral health over losing their daily wages and leaving their workplace to get a checkup done.

Conveyance and domestic issues were reported more amongst females and older males which is similar to the studies conducted in India. ${ }^{20}$ This shows that majority of women in this country are not self-reliant and depend on a companion to travel to the hospital. Also, women, mainly housewives find themselves caught up in the day's work at their homes; taking care of the kids, cooking, cleaning etc. and so find it difficult to take out time for their dental visits. The same can be said about the older population, as they are frail and dependent on someone and too require assistance to be taken to the hospital.

According to a study conducted in Karachi, Pakistan, females are more dentally fearful than males. ${ }^{21}$ This is consistent with the findings in our research where more females stated dental phobia as the reason for delayed visit as compared to males. According to another research conducted in Pakistan, females had higher anxiety levels for dental treatment as indicated by a greater Dental Anxiety Score (DAS). ${ }^{22}$ This can be attributed to the conventional gender roles that exist within our society due to which males tend to suppress their feelings and fears while females are more expressive. ${ }^{22}$
The most common reason for delay in old aged individuals was health issues. This information is also cohesive with the results of a research conducted in Taibah University, Saudi Arabia. ${ }^{23}$ Diseases like diabetes, chronic back pain and cardiovascular disorders debilitate the patient and severely limit their mobility and general function. These also contribute to low self-care/ self-efficacy leading to insufficient utilization of dental care services. ${ }^{24}$

This research gives us valuable information that can be used by public health officials and health care providers to improve awareness, acceptability, knowledge and most importantly access to oral health care amongst the general Pakistani population. This can be achieved through targeted dental awareness campaigns including dental camps, leaflets etc. Efforts should also be directed towards formulation and implementation of policies that will prevent the abuse of medications especially antibiotics.

The limitations of this study are the sampling method and localization of the study area. Since the sample consisted mainly of individuals belonging to the low socioeconomic class and limited education, inclusion of people from wellendowed backgrounds could have affected the results.

\section{CONCLUSION}

More than half of the study population had not visited the dentist when the symptoms first appeared and presented with irreversible tooth damage that required extraction of the tooth. Pain and swelling were the major factors that compelled them to finally visit the dentist. Selfmedication, symptoms will resolve on their own \& lack of awareness of dental treatment were the strongest predictors for nonattendance behavior. Copyright $@ 21$ Dec, 2020.

\section{REFERENCES}

1. Yao K, Yao Y, Shen X, Lu C, Guo Q. Assessment of the oral health behavior, knowledge and status among dental and medical undergraduate students: A cross-sectional study. BMC oral health. 2019 Dec; $19(1): 1-8$. 
2. Nazir MA. Prevalence of periodontal disease, its association with systemic diseases and prevention. International journal of health sciences. 2017 Apr; $11(2): 72$.

3. Cardoso EM, Reis C, Manzanares-Céspedes MC. Chronic periodontitis, inflammatory cytokines, and interrelationship with other chronic diseases. Postgraduate medicine. 2018 Jan 2; 130(1):98-104.

4. Obeidat SR, Alsa'di AG, Taani DS. Factors influencing dental care access in Jordanian adults. BMC Oral Health. 2014 Dec 1; 14(1):127.

5. Lee Y. Diagnosis and prevention strategies for dental caries. Journal of lifestyle medicine. 2013 Sep; 3(2):107.

6. Fotedar S, Sharma KR, Bhardwaj V, Sogi GM. Barriers to the utilization of dental services in Shimla, India. European Journal of General Dentistry. 2013 May 1; 2(2):139.

7. Nagarjuna $P$, Reddy VC, Sudhir KM, Kumar RK, Gomasani S. Utilization of dental health-care services and its barriers among the patients visiting community health centers in Nellore District, Andhra Pradesh: A cross-sectional, questionnaire study. Journal of Indian Association of Public Health Dentistry. 2016 Oct $1 ; 14(4): 451$.

8. Onyejaka NK, Folayan MO, Folaranmi N. Barriers and facilitators of dental service utilization by children aged 8 to 11 years in Enugu State, Nigeria. BMC health services research. 2016 Dec 1; 16(1):93.

9. Yarbrough $\mathrm{C}$, Nasseh K, Vujicic M. Why adults forgo dental care: Evidence from a new national survey. Health Policy Institute Research Brief. American Dental Association. November. 2014 Nov.

10. Australian Research Centre for Population Oral Health. The avoidance and delaying of dental visits in Australia. Australian dental journal. 2012 Jun; 57(2):243-7.

11. Fotedar S, Sharma KR, Bhardwaj V, Sogi GM. Barriers to the utilization of dental services in Shimla, India. European Journal of General Dentistry. 2013 May 1; 2(2):139.

12. Ahmed W, Bukhari SF, Aslam M. Barriers in access and utilization of dental care: Assessment and recommendations using Delphi technique. JPDA. 2019 Jan; 28(01):14.

13. Saleem F, Ashraf S, Javed F, Naveed M. Determinants of delay in presentation of patients with dental problems. Pakistan Journal of Medical \& Health Sciences. 2018 Jul 1; 12(3):1211-3.
14. Patel KH, Nair VS, Kalra DD, Shetty V. Cultural and socioeconomic barriers in utilization of dental services: A cross sectional questionnaire based study. National Journal of Community Med. 2016; 7(10):807- 810

15. Anyanechi CE, Saheeb BD. Reason's underlying failure to seek early dental treatment among patients presenting in a Nigeria Tertiary Hospital. Journal of Medicine and Biomedical Research. 2013 Aug 6; 12(1):37-45.

16. Hemani A, Rauf F, Noori MY, Faisal A. Barriers to the access of oral health care in individuals from lower socioeconomic communities in Karachi. Journal of the Liaquat University of Medical and Health Sciences. 2017 Oct $1 ; 16(4): 218-21$.

17. Zangiabadi S, Costanian C, Tamim H. Dental care use in Ontario: The Canadian community health survey (CCHS). BMC oral health. 2017 Dec 1; 17(1):165.

18. Baskaradoss JK. Relationship between oral health literacy and oral health status. BMC Oral Health. 2018 Dec $1 ; 18(1): 172$.

19. Al-Shammari KF, Al-Ansari JM, Al-Khabbaz AK, Honkala S. Barriers to seeking preventive dental care by Kuwaiti adults. Medical Principles and Practice. 2007; 16(6):413-9.

20. Kakatkar G, Bhat N, Nagarajappa R, Prasad V, Sharda A, Asawa K, Agrawal A. Barriers to the utilization of dental services in Udaipur, India. Journal of Dentistry (Tehran, Iran). 2011; 8(2):81.

21. Wali A, Ali SA, Siddiqui TM, Farzand M, Malik L. Assessment of anxiety in patients attending Baqai Dental Teaching Hospital Karachi-a cross sectional study. Journal of Bahria University Medical \& Dental College. 2019; 9:34-7.

22. Farooq I, Ali S. A cross sectional study of gender differences in dental anxiety prevailing in the students of a Pakistani dental college. The Saudi Journal for Dental Research. 2015 Jan 1; 6(1):21-5.

23. Alkhalifa NS, Zahran DH. Reasons preventing or delaying dental visits in Taibah University students. Journal of Advances in Medicine and Medical Research. 2016 Feb 22:1-8.

24. Spinler K, Aarabi G, Valdez R, Kofahl C, Heydecke G, König $\mathrm{HH}$, Hajek A. Prevalence and determinants of dental visits among older adults: Findings of a nationally representative longitudinal study. BMC health services research. 2019 Dec 1; 19(1):590. 


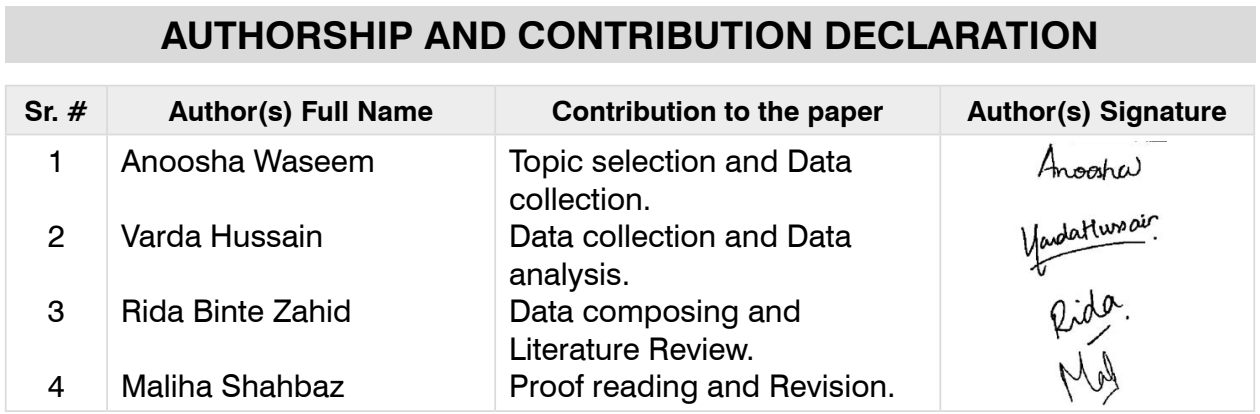

